\title{
Predictors of arterial ischemic stroke outcome in children
}

\section{Summary}

There are limited knowledge and controversies on prognostic factors for outcome. It has been shown that the long-standing believe that younger children have better prognosis has to be revised. ${ }^{1}$ Neuroimaging might play a major role for prognosis, but knowledge is still limited.
Volume 9 Issue 3 - 2019

\section{Tatia Aprasidze \\ Neuroscience Department, David Tvildiani Medical University, Georgia}

Correspondence: Tatia Aprasidze, Neuroscience Department at M. lashvili Children's Central Hospital,Tbilisi, Georgia, Email tatia_afrasidze@yahoo.com

\section{Introduction, Aim}

Research on peadiatric stroke has become increasingly more important over the last decade. Recent studies suggest an incidence of childhood stroke of 2-5/100.000 children per year. ${ }^{2}$ Despite its low incidence, stroke ranks among the top 10 causes of death in children. ${ }^{3}$ In more than half of the surviving children who had a stroke, the risk of motor, behavioral and cognitive disorders and epilepsy results in major long-term personal, family and social consequences. ${ }^{4,5}$ The condition carries a risk of recurrence in approximately $10-20 \%$ of cases. ${ }^{1,6}$ Mortality rate of pediatric arterial ischemic stroke (AIS) ranges from $10-20 \%{ }^{7}$ and may be higher in recurrent stroke. No estimates of pediatric stroke burden are available for Georgia. The aim of the study is to evaluate outcome of children with arterial ischemic stroke (AIS) and explore predictive factors that affect outcome.

\section{Methods}

\section{Population}

Children aged of 1 month to 17 years with the diagnosis of arterial ischemic stroke, proved by magnetic resonance imaging (MRI), who were treated at M. Iashvili Children's Central Hospital, with the onset of stroke from 2009 were included.

An exclusion criterion was transient ischemic attack (TIA), patients who had ischaemic stroke within the first month of life, and incomplete records.

\section{Data collection}

Data were collected from hospital records and included demographic characteristics, clinical data, and neurological impairments at onset, affected arteries, vascular distribution areas involved, possible causes and risk factors for stroke, presence of stroke recurrence and status at discharge.

Outcome was evaluated using Pediatric Stroke Outcome Measure (PSOM), which is based upon a clinical neurological examination. ${ }^{8}$ Neurologic deficit severity based on the scores: A deficit score ranging from 0 to $2(0=$ no deficit; $0.5=$ mild deficit but no impact on function; $1=$ moderate deficit with some functional limitations; $2=$ severe deficit with missing function) was assigned for each of the following 5 'spheres': (a) right sensorimotor and (b) left sensorimotor (both including visual, hearing, motor and somatosensory function); (c) language production; (d) language comprehension; (e) cognitive and behavioral performance. The sum of the scores of the five subscales is a total score ranging from 0 to $10 .^{8}$ The authors of the scale of PSOM have classified outcome as 'favourable' if the child had no impairments (score 0.5 in only one of five domains) and in other instances, outcome was categorized as 'unfavourable' (i.e. two or more 0.5 scores, or at least one score of 1 or $2 .{ }^{8}$

\section{Results}

50 patients $(25 \mathrm{male} / 25 \mathrm{female})$ were investigated. The most -31 of childhood stroke cases were obtained in patients aged 1 month to 4years, followed by 11 patients in the age group of 4 to 9 years and 8 aged 10 to 17 years.

\section{Symptoms at presentation}

The main clinical signs were hemiparesis in $38(76 \%)$ patients, leftsided in 22 and right-sided in 16. Seizures were presenting symptom in $23(46 \%)$ cases, facial palsy in $17(34 \%)$, aphasia in $13(26 \%)$, headache in $12(24 \%)$, cognitive and behavioral deficit in $12(24 \%)$, low level of consciousness (LOC) - in 10(20\%), vomiting in 6(12\%), fever in $6(12 \%)$, ataxia in $2(4 \%)$ and visual field deficit in $2(4 \%)$ patients.

\section{Radiological features}

Of the 50 children 40 had isolated infarction and 10 had multiple infarction; In 39/50 cases territory of middle cerebral artery was affected, in 1 - anterior cerebral artery (ACA), and 10 had involvement of posterior cerebral artery (PCA); $26 / 50$ patients suffered from stroke in the left hemisphere, $15 / 50$ had a right-sided stroke and 9/50 patients had bilateral stroke; Combined cortical and subcortical infarction was detected in 10 patients; Large arteries were affected in 30, small arteries in 20 cases; Hemorrhagic component was found in 8 patients (Table 1).

\section{Risk factors}

Risk-factors were identified in 17/50 (34\%) patients: In the group of vasculopathies 3 patients were diagnosed with moya-moya disease, 1 had arterial dissection; Cardiopathy occurred in 4 patients; In the group of systematic disease 1 child had renal disorder and arterial hypertension, 1 - MELAS, 1 patient was with Sturge-Weber syndrome; 
3 patients were diagnosed with encephalitis, 3 had Varicella infection 3-12 months prior the stroke; 1 patient was suspected to have vasculitis.

Table I Radiological features

\begin{tabular}{ll}
\hline Radiological features & $\mathbf{N}(\%)$ \\
\hline Multiple stroke & $10 / 50(20 \%)$ \\
Bilateral stroke & $9 / 50(18 \%)$ \\
Unilateral stroke: Left hemisphere/right hemisphere & $63 \% / 37 \%$ \\
Anterior circulation/Posterior circulation/Both & $80 \% / 12 \% / 8 \%$ \\
Basal ganglia MCA/Cortical MCA/Subcortical MCA & $42 \% / 44 \% / 70 \%$ \\
Massive MCA stroke & $7 / 50(14 \%)$ \\
Anterior Cerebral Artery(ACA) & $1 / 50(2 \%)$ \\
Posterior Cerebral Artery(PCA) & $10 / 50(20 \%)$ \\
Artery size: Large & $30(60 \%)$ \\
$\quad$ Small & $20(40 \%)$ \\
Hemorrhagic component & $8(16 \%)$ \\
Recurrence & $5(20 \%)$ \\
\hline
\end{tabular}

Status at discharge: From 50 patients 8 had no deficit at discharge.

Outcome: Long-term outcome was assessed $\geq 1$ year after stroke (1 to 7years). The results of the PSOM subscales are shown in Figure 1. Deficit was more frequent on the right side than on the left side, and it was moderate or severe. Language deficit occurred in $8(32 \%)$, and cognitive and behavioral deficit in $12(48 \%)$ patients. The results of total PSOM score are shown in Figure 2. The outcome based on PSOM assessment: no deficit, 20(40\%); mild deficit, 5(10\%); moderate deficit, 19(38\%); and severe deficit, 6(12\%). Stroke recurrence occurred in 5(10\%) patients. According to PSOM scores neurological outcome was favorable in $50 \%$ of patients $(20$ without and 5 with mild neurological deficits), and unfavorable in $50 \%$ with moderate to severe deficits. Epilepsy at evaluation was reported in 6 patients.

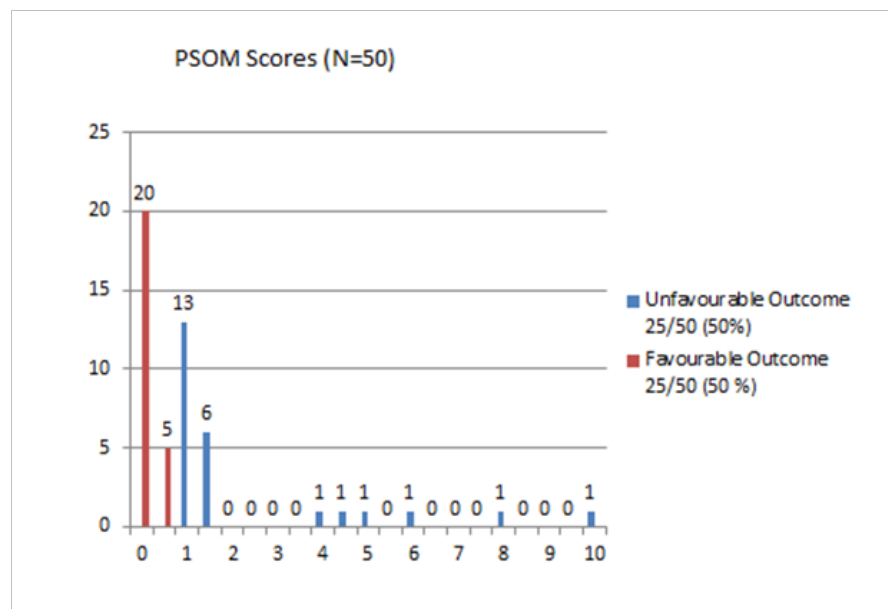

Figure I Score of the subscales ( 0 no deficit, 0.5 mild deficit, I moderate deficit, 2 severe deficit).
Predictive factors for outcome were assessed according to PSOM results. Prognosis was unfavorable in $50 \%$ of children, with moderate to severe deficits. The factors that had an influence on outcome are shown in Table 2.

\section{Table 2 PSOM results}

\begin{tabular}{|c|c|c|}
\hline $\operatorname{AIS}(n=50)$ & $\begin{array}{l}\text { Favorable } \\
\text { outcome } \\
\mathrm{N}=25(50 \%)\end{array}$ & $\begin{array}{l}\text { Unfavorable } \\
\text { outcome } \\
\mathrm{N}=\mathbf{2 5}(50 \%)\end{array}$ \\
\hline $\begin{array}{l}\text { Age at stroke: I mo to } \\
\text { 4years }\end{array}$ & $12(48 \%)$ & $19(76 \%)$ \\
\hline 5 to 9 years & $8(32 \%)$ & $3(12 \%)$ \\
\hline 10 to $17 y$ years & $5(20 \%)$ & $3(12 \%)$ \\
\hline $\begin{array}{l}\text { Recurrent stroke } \\
n=5(10 \%)\end{array}$ & $2(8 \%)$ & $3(12 \%)$ \\
\hline $\begin{array}{l}\text { Hemiparesis at } \\
\text { presentation } n=38\end{array}$ & $4(16 \%)$ & $23(92 \%)$ \\
\hline Epilepsy at evaluation & $4(16 \%)$ & $2(8 \%)$ \\
\hline Basal ganglia $N=2$ I & $13(52 \%)$ & $8(32 \%)$ \\
\hline $\begin{array}{l}\text { Cortical and subcortical } \\
\text { involvement }\end{array}$ & $2(8 \%)$ & $8(32 \%)$ \\
\hline Massive MCA stroke & $2(8 \%)$ & $5(20 \%)$ \\
\hline Large artery $n=30$ & II (44\%) & $19(76 \%)$ \\
\hline Small artery $n=20$ & $14(56 \%)$ & $6(24 \%)$ \\
\hline
\end{tabular}

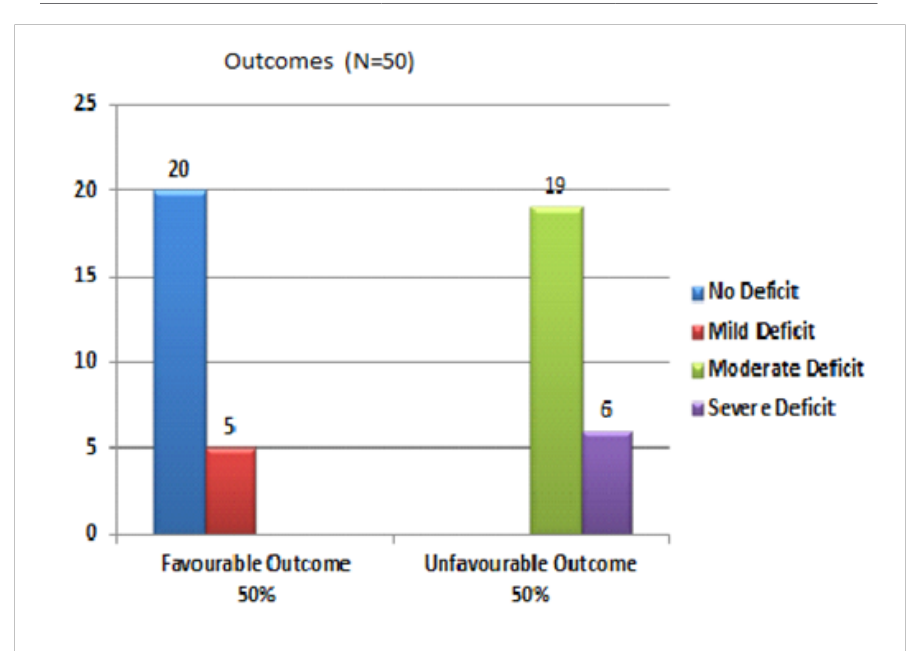

Figure 2 Results of total PSOM score.

\section{Discussion}

According to our study outcome was worse in patients with younger ages at stroke. Even if it is widely believed that brain plasticity can lead to improved outcome following acquired brain injury at an early age, there is increasing evidence to support the hypothesis that younger age at time of stroke is a predictor of a worse outcome, particularly for cognitive and neuropsychological domains. ${ }^{8,10}$ Our results are similar to other authors, regarding stroke size and cortical and subcortical involvement association with poor outcome. No significant relationship was found between prognosis of 
stroke and gender, risk-factors, stroke recurrence, bilateral, multiple stroke and hemorrhagic component. Epilepsy wasn't associated with poor outcome.

\section{Conclusion}

Stroke is a cause of significant morbidity with moderate to severe deficits in half of the patients. Younger age, lesion size was associated with poor outcome. Our study is still ongoing study. It is planned to investigate more patients in terms of long-term cognitive outcome.

\section{Acknowledgments}

None.

\section{Conflicts of interest}

Author Declare their are no conflicts of interest.

\section{References}

1. Maja Steinlin. A Clinical Approach to Arterial Ischemic Childhood Stroke: Increasing Knowledge over the last decade. Neuropediatrics. 2012;43(1):1-9.

2. Amlie Lefond C, Sébire G, Fullerton HJ. Recent developments in childhood arterial ischaemic stroke. Lancet Neurol. 2008;7(5):425-435.
3. Beslow LA, Jordan LC. Pediatric stroke: the importance of cerebral arteriopathy and vascular malformations. Childs Nerv Syst. 2010;26(10):1263-1273.

4. Mallick AA, O'Callaghan FJ. The epidemiology of childhood stroke. Eur J Paediatr Neurol. 2010;14(3):197-205.

5. Mallick AA, Ganesan V, Kirkham FJ, et al. Childhood arterial ischaemic stroke incidence, presenting features, and risk factors: a prospective population_based study. Lancet Neurol. 2014;13(1):35-43.

6. Jones BP, Ganesan V, Saunders DE, et al. Imaging in childhood arterial ischaemic stroke. Neuroradiology. 2010;52(6):577-589.

7. Christerson S, Strömberg B. Stroke in Swedish children II: longterm outcome. Acta Paediatr. 2010;99(11):1650-1656.

8. Paediatric Stroke Working Group. Stroke in childhood: clinical guidelines for diagnosis, management and rehabilitation. 2004.

9. Vázquez López M, de Castro de Castro P, Barredo Valderrama E, et al. Outcome of arterial ischemic stroke in children with heart disease". Eur J Paediatr Neurol. 2017;21(5):730-737.

10. Mallick AA, O'Callaghan FJ. Risk factors and treatment outcomes of childhood stroke. Expert Rev Neurother. 2010;10(8):1331 1346. 